\title{
PHASE EQUILIBRIA IN THE SYSTEM $\mathrm{SiO}_{2}-\mathrm{ZnO}$
}

\author{
By E. N. Bunting
}

ABSTRACT

A study of phase equilibria in the condensed system $\mathrm{SiO}_{2}-\mathrm{ZnO}$ by the quenching method shows the existence of $(a)$ only one compound, $\mathrm{Zn}_{2} \mathrm{SiO}_{4}$, the melting point of which is $1,512^{\circ} \mathrm{C}$; $(b)$ a region of two immiscible liquid phases in equilibrium with cristobalite at $1,695^{\circ} \mathrm{C}$., extending from 2 to $35 \mathrm{~mol}$ per cent $\mathrm{ZnO}$; (c) a eutectic between tridymite and $\mathrm{Zn}_{2} \mathrm{SiO}_{4}$ at $1,432^{\circ} \mathrm{C}$. and 49.1 mol per cent $\mathrm{ZnO}$; and $(d)$ a eutetic between $\mathrm{ZnO}$ and $\mathrm{Zn}_{2} \mathrm{SiO}_{4}$ at $1,507^{\circ} \mathrm{C}$. and $77.5 \mathrm{~mol}$ per cent $\mathrm{ZnO}$. The melting point of $\mathrm{ZnO}$ is found to be $1,975^{\circ} \pm 25^{\circ} \mathrm{C}$.

An iridium vessel is described which can be used in an induction furnace to obtain constant temperatures up to $2,300^{\circ} \mathrm{C}$, in an oxidizing atmosphere.

\section{CONTENTS}

I. Introduction

II. General method

III. The $\mathrm{SiO}_{2}-\mathrm{ZnO}$ mixtures

IV. Results

V. Discussion

VI. The melting point of $\mathrm{ZnO}$

\section{INTRODUCTION}

Since the available data on phase equilibria in the $\mathrm{SiO}_{2}-\mathrm{ZnO}$ system were very incomplete and contradictory, a rather complete study of this system has been made as a preliminary to an investigation of the ternary system $\mathrm{SiO}_{2}-\mathrm{ZnO}-\mathrm{Al}_{2} \mathrm{O}_{3}$.

The existence of a zinc metasilicate, $\mathrm{ZnSiO}_{3}$, has been reported by several investigators. ${ }^{1}$ Gorgeu, ${ }^{2}$ however, could not obtain the metasilicate from melts of $\mathrm{ZnO}+\mathrm{SiO}_{2}$ with $\mathrm{Na}_{2} \mathrm{SO}_{4}$, only the orthosilicate being formed.

The orthosilicate, $\mathrm{Zn}_{2} \mathrm{SiO}_{4}$, is found as the mineral willemite. Stein gives the melting point of the synthetic compound as $1,484^{\circ} \mathrm{C}$. and Jäger and van Klooster give $1,509^{\circ} \mathrm{C}$.

\section{GENERAL METHOD}

Because of the low velocity of crystallization of molten silicate mixtures it was necessary to use the quenching method to study the equilibrium conditions. A small sample (10 to $20 \mathrm{mg}$ ) of the mixture under investigation was inclosed in a platinum capsule and

1 Stein, Zeit. anorg. Chem., 55, p. 159; 1907. van Klooster, Zeit. anorg. Chem., 69, p. 142; 1910. Jäger and van Klooster, Proc. Royal Acad. Sci. Amst., 18, p. 896; 1916. Ebelmen, Ann. de Chim. Phys. (3), 33, p. 34; 1851. Schulze and Stelzner, Neues Jahrb. Min., 1, p. 150; 1881. Traube, Berichte, 26, p. 2735; 1893. Mulert, Zeit. anorg. Chem., 75, p. 220; 1912. Rüger, Keram. Rundschau, 31, p. 100; 1923.

${ }^{2}$ Gorgeu, Comp. rend., 104, p. 120; 1887. 
held at a constant temperature until equilibrium was attained between the phases present. It was then rapidly cooled by dropping into water or mercury, so that no change in the equilibrium could occur, and the material examined under the petrographic microscope to identify the phases present.

Figure 1 shows the resistance furnace used. It was $40 \mathrm{~cm}$ long and the heating unit consisted of $13.7 \mathrm{~m}$ of wire, ${ }^{3} 0.81 \mathrm{~mm}$ in diameter,

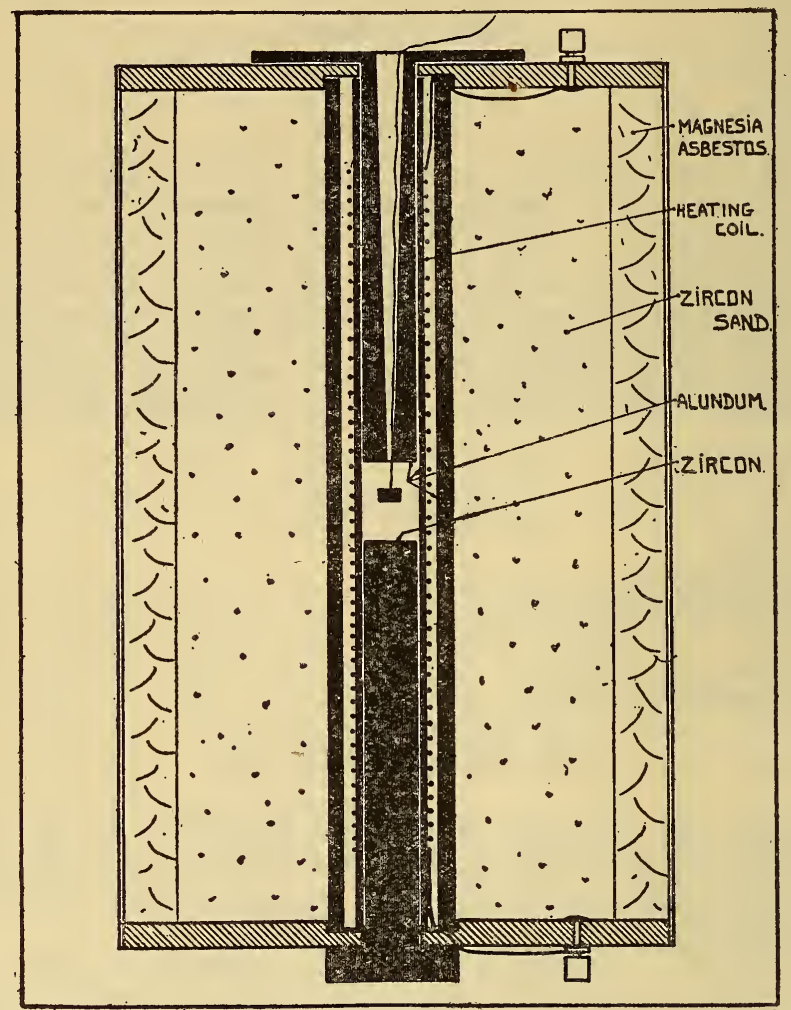

FIGURE 1.-Diagram of $P t-R h$ resistance furnace used in quenching experiments

made from an alloy containing 60 per cent $\mathrm{Pt}$ and 40 per cent $\mathrm{Rh}$. About $1 \mathrm{kw}$ was required to hold it at $1,700^{\circ} \mathrm{C}$. The platinum capsule was suspended in the furnace chamber by means of a fine platinum wire attached to a larger platinum wire. After equilibrium was attained the bottom plug was removed and the capsule dropped into water by pulling it up until its small supporting wire broke. Temperatures in the furnace were held constant with a modified thermostat of the type developed at the Geophysical Laboratory, ${ }^{4}$ and were measured with a disappearing filament optical pyrometer sighted through the conical opening in the upper plug of the furnace. A calibrated Pt-PtRh thermocouple ${ }^{5}$ placed in the center of the furnace

3 The wire was fabricated by the chemical metallurgy section of this bureau. Recently pure rhodium wire has been used as the heating unit.

Roberts, J. Opt. Soc. Am. and Rev. Sci. Inst., 11, p. 171; 1925

The optical pyrometer and thermocouple were calibrated by the pyrometry section of this bureau. 
chamber checked the temperature readings obtained with the optical pyrometer to within $2^{\circ} \mathrm{C}$. at $1,400^{\circ} \mathrm{C}$., both pyrometer and thermocouple being certified to $\pm 5^{\circ} \mathrm{C}$. at this temperature. At the higher temperatures up to $1,700^{\circ} \mathrm{C}$. the pyrometer was certified to $\pm 10^{\circ} \mathrm{C}$.

\section{THE $\mathrm{SiO}_{2}-\mathrm{ZnO}$ MIXTURES}

The $\mathrm{SiO}_{2}-\mathrm{ZnO}$ mixtures investigated were prepared from selected rock crystal (99.7 per cent $\mathrm{SiO}_{2}$ after grinding to 200 mesh) and zinc oxide specially prepared by the New Jersey Zinc Co. and containing not more than 0.10 per cent total impurities. ${ }^{6}$ The mixtures were prepared in stick form and prefused in the oxyhydrogen flame. The fused material was pulverized in a steel mortar and ground in an agate mortar. Three fusions and grindings were made to insure a homogeneous mixture. ${ }^{7}$ All mixtures were found to contain one to twotenths of a per cent of $\mathrm{Fe}_{2} \mathrm{O}_{3}$, introduced in the pulverizing process. The mixtures were all held at the furnace temperatures for one-half hour or more before quenching.

\section{RESULTS}

The data obtained are given in the table and in Figure 2.

Results with $\mathrm{SiO}_{2}-\mathrm{ZnO}$ mixtures

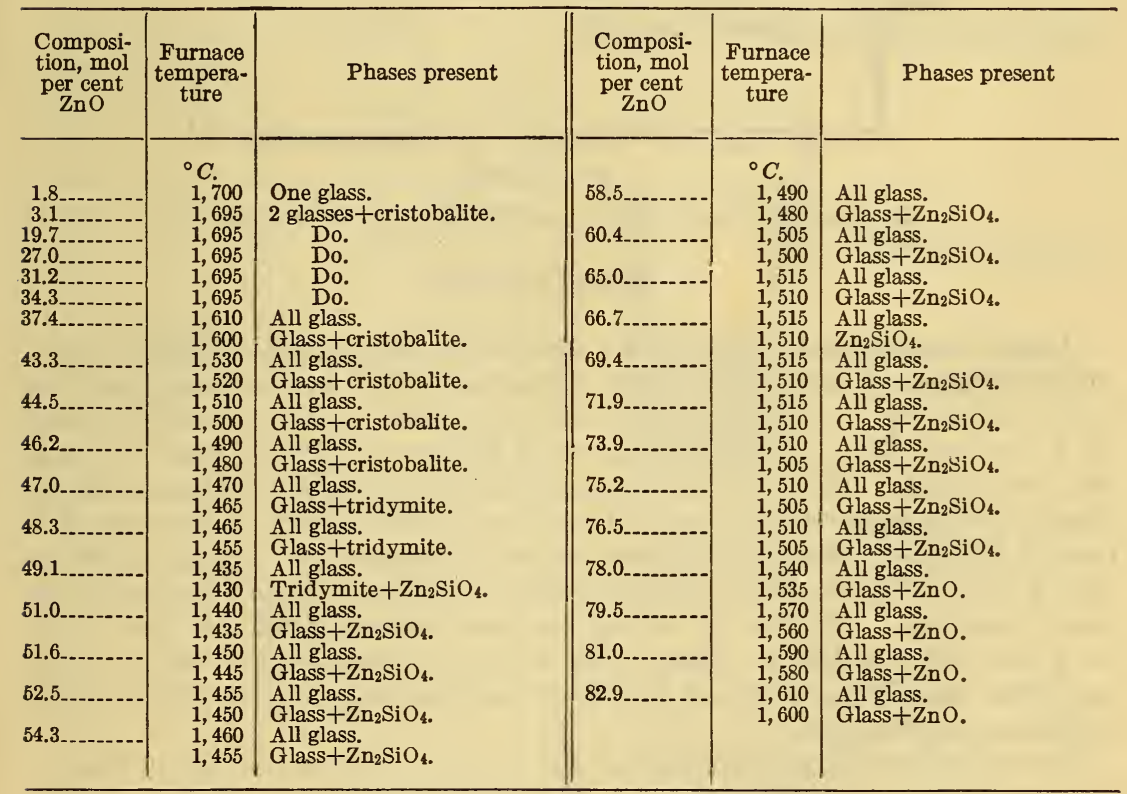

6 Analysis furnished by the New Jersey Zinc Co.

7 All mixtures were analyzed by J. A. Scherrer of the analytical section of the chemistry division of this bureau. 


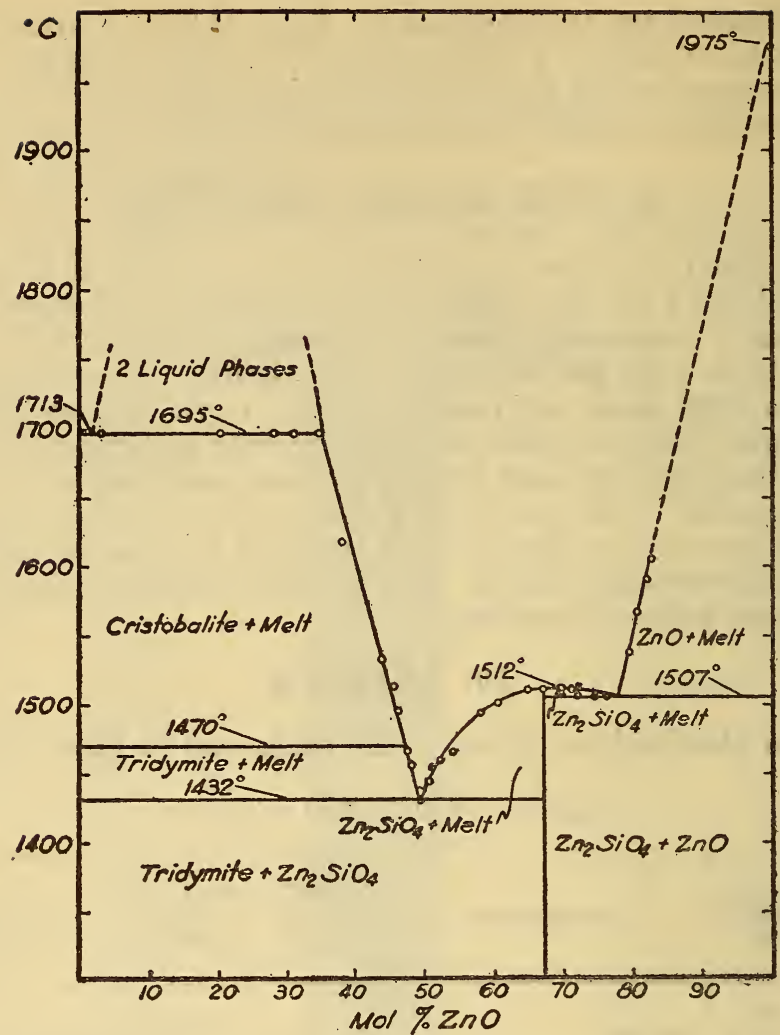

Figure 2.-Phase diagram for the system $\mathrm{SiO}_{2}-\mathrm{ZnO}$

\section{DISCUSSION}

These experiments show that only one compound $-\mathrm{Zn}_{2} \mathrm{SiO}_{4}$, zinc orthosilicate-is formed at high temperatures. Its melting point is $1,512^{\circ} \mathrm{C} \pm 3^{\circ} \mathrm{C}$. It forms a eutectic with tridymite at $1,432^{\circ} \mathrm{C}$. and 49.1 per cent $\mathrm{ZnO}$, and a eutectic with $\mathrm{ZnO}$ at $1,507^{\circ} \mathrm{C}$. and $77.5 \mathrm{~mol}$ per cent $\mathrm{ZnO}$. The optical properties of the $\mathrm{Zn}_{2} \mathrm{SiO}_{4}$ prepared agree closely with those of the natural mineral, willemite, ${ }^{8}$ and are as follows: ${ }^{9}$ Uniaxial positive (tetragonal or hexagonal) occurring as irregular grains with no characteristic crystal form or habit and with no good cleavage. Indices of refraction for sodium light are $\omega=1.692$, $\epsilon=1.720$, both \pm 0.003 . Near the eutectic composition with tridymite the $\mathrm{Zn}_{2} \mathrm{SiO}_{4}$ occurs as fine fibrous crystals, often as spherulitic radiating aggregates.

No evidence of the existence of the metasilicate was found. Examination at high magnification $(1,000 \times)$ of the fully crystallized mixtures containing 49.1 and $51.0 \mathrm{~mol}$ per cent of $\mathrm{ZnO}$ held at $1,350^{\circ}$, $1,300^{\circ}, 1,200^{\circ}$, and $1,100^{\circ}$ C., respectively, for 70 hours each, showed them to contain only tridymite (25 to 30 per cent) and zinc ortho-

8 Am. Mineral, 10, p. 187; 1927.

H. Insley, of this bureau, determined the optical properties and collaborated in the petrographic exam. ination of some of the mixtures.3 
silicate. $^{10}$ At a magnification of 100 to $200 \times$, the material appears to be homogeneous and might easily be mistaken for a metasilicate. These same mixtures were also fused with sodium tungstate at $1,000^{\circ}$ for 72 hours and the melt extracted with warm water and dilute ammonia solution. Only zinc orthosilicate was found in the residue. X-ray spectrograms ${ }^{11}$ of the mixtures, containing $51.6 \mathrm{~mol}$ per cent $\mathrm{ZnO}$, quenched at $1,440^{\circ} \mathrm{C}$., and $65.0 \mathrm{~mol}$ per cent $\mathrm{ZnO}$, quenched at $1,505^{\circ} \mathrm{C}$., showed identical patterns, proving the absence of a metasilicate in the region of $50 \mathrm{~mol}$ per cent $\mathrm{ZnO}$. X-ray spectrograms of the $48.3 \mathrm{~mol}$ per cent $\mathrm{ZnO}$ and $51.6 \mathrm{~mol}$ per cent $\mathrm{ZnO}$ mixtures held at $1,350^{\circ} \mathrm{C}$. for two hours and containing tridymite with zinc orthosilicate were also identical.

The two liquid phases occurring at $1,695^{\circ}$ and between 2 to $35 \mathrm{~mol}$ per cent $\mathrm{ZnO}$ were first noted by J. W. Greig. ${ }^{22}$ The upper boundary of this region was not investigated, as it is above the temperature attainable in the resistance furnace. The Ir-Pt alloy furnace described below (fig. 3) could not be used for this purpose, as vaporization from the hole at high temperatures could not be prevented, and the mixture in the hole did not remain of uniform composition.

The melting point of cristobalite given as $1,713^{\circ} \mathrm{C}$., in figure 2 , is taken from the data published by J. W. Greig. ${ }^{13}$

\section{THE MELTING POINT OF $\mathrm{ZnO}$}

The only datum given in the literature on the melting point of $\mathrm{ZnO}$ is that it is above $1,800^{\circ} \mathrm{C} .^{14}$ As this is above the temperature obtainable in a platinum resistance furnace, it was necessary to design a furnace which could be operated at high temperatures in an oxidizing atmosphere in order to prevent the reduction of the $\mathrm{ZnO}$. Iridium, with a melting point of $2,300^{\circ} \mathrm{C}$., is a suitable heating element, since it does not oxidize when heated rapidly to temperatures above $1,200^{\circ} \mathrm{C} . .^{15} \mathrm{In}$ stead of pure iridium, an alloy with 27 per cent platinum, melting at $2,150^{\circ} \mathrm{C}$., was employed in the form of a button which was formed by melting mixed Ir-Pt sponge in the bottom of a thoria crucible. ${ }^{16}$ (See fig. 3.) When this crucible was sur-

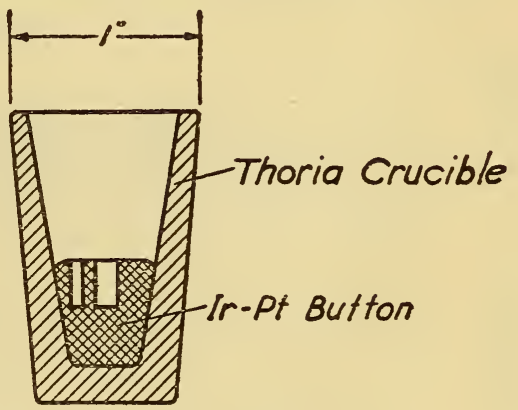

FIgURE 3.-Crucible with iridium vessel used to obtain temperatures up to $2,300^{\circ} \mathrm{C}$. in an oxidizing atmosphere rounded with an insulating layer of powdered thoria one-half inch thick, contained in an alundum thimble, the button within could be heated up to its melting point when placed in the high-frequency field of an Ajax induction furnace. By adjusting the spark gap every minute or two the temperature of the button could be held constant

\footnotetext{
10 See footnote 9.

11 X-ray spectrograms were made by E. C. Groesbeck, of the metallurgical division of this bureau.

12 Greig, Am. J. Sci., 13, p. 137; 1927.

13 Greig, Am. J. Sci., 13, p. 10; 1927.

14 Libman. J. Am. C̈eram. Soc., 5, p. 488; 1922

16 The dissociation temperature of $\mathrm{IrO}_{2}$. See Becker, Diss. Darmstadt; 1927.

16 This crucible and Ir button were fabricated by the chemical metallurgy section of this bureau.
} 
within $\pm 10^{\circ} \mathrm{C}$. Temperatures were measured with an optical pyrometer sighted on the outer small hole, both holes giving the same reading when empty.

A small piece of $\mathrm{ZnO}$, which had previously been fused in the oxygen carbon arc, was placed in the center hole of the button and heated. Above $1,950^{\circ} \mathrm{C}$. complete evaporation of the charge occurred within a few seconds. However, when a layer of $\mathrm{Ir}-\mathrm{Pt}$ sponge (of the same composition as the button) was tamped in above the powdered $\mathrm{ZnO}$, a fused pellet of $\mathrm{ZnO}$ was obtained on heating to $1,975^{\circ}$ for a few seconds. A repetition of this procedure at $1,960^{\circ}$ did not fuse the $\mathrm{ZnO}$, while at $1,985^{\circ}$ a fused pellet was also obtained. The optical pyrometer was used immediately after calibration and was certified to $\pm 25^{\circ} \mathrm{C}$. at this temperature.

The author is indebted to $\mathrm{E}$. W. Washburn, of this bureau, under whose general supervision the work was done.

Washington, September 4, 1929. 